\title{
THE IMPACTS OF ETHICAL LEADERSHIP ON THE ANTISOCIAL BEHAVIOR OF EMPLOYEES: THE MEDIATING ROLE OF ETHICAL CLIMATE
}

\author{
*Meral Elçi \\ **İ̈ge Şener \\ *Lütfihak Alpkan \\ *Gebze Institute of Technology, Turkey \\ *Çankaya University, Turkey
}

\begin{abstract}
Antisocial behaviors of employees lead to unfavorable outcomes for the organization. Creating an ethical environment through developing ethical leadership and building an ethical environment in the organizations, the antisocial behaviors of employees could be decreased. With this study, it was intended to investigate the effect of both ethical leadership and ethical climate on the occurrence of antisocial behaviors of employees. Using a sample of 468 employees in 30 firms operating in various industries in Istanbul, Kocaeli, Ankara and Antalya from Turkey, we find support for the hypothesized model. The findings of the research indicate a negative effect of presence of ethical leadership on the antisocial behaviors of employees. Besides, ethical climate both has a negative effect on antisocial behaviors of employees and also it mediates the relationship between ethical leadership and the antisocial behaviors of employees.
\end{abstract}

Keywords: ethical leadership, ethical climate, workplace antisocial behavior, mediation effects

\section{INTRODUCTION}

Forestalling of antisocial behaviors in organizations is increasingly becoming important to the managers and organizational scholars. According to the report of Di Martino et al (2003:1), recent estimates suggest a good reason for both managers and researchers to take a closer look at these actions. This is due to the economy becoming more global and increasing competition for market shares and survival, which leads to pressures mounting on workers. The authors state that, with relatively high levels of crime in most EU countries, violence finds its way into the workplace in the form of robbery and assault, particularly affecting front-line staff and service-providers. Along with growing pressure, aggression may also build up within the workplace, making violence between workers more likely. On the other hand, occupational stress has in recent years assumed epidemic proportions, affecting workers across most sectors and industries; violence may be an important source of stress, but may also result from a stressful working environment. However, recent European studies indicate that it is psychological violence and harassment, rather than physical violence, which represents the greatest threat to most workers. Due to the increasing diversity of the workforce, a number of studies also show the frequent presence of harassment on the basis of race or gender (Di Martino et al, 2003:1).

A comprehensive report of sexual harassment in EU countries was compiled for the European Commission in 1998. According to this report, between $30 \%-50 \%$ of female employees have experienced some form of sexual harassment. When the particular type of harassment was considered, $10 \%-26 \%$ of them were found to have experienced so-called quid pro quosexual harassment and $1 \%-6 \%$ of them experienced severe forms of sexual harassment, such as assault or rape. The same study also concluded that, comparatively speaking, much fewer studies had been undertaken in southern European countries as opposed to northern Europe (Di Martino et al, 2003: 39).

The results of a Spanish study (Piñuel y Zabala, 2002) combining two samples of a broad sector-wide sample and a sample from the tourism sector, reveals important findings. One of the key findings of the study is that a total of $16 \%$ of the sample were found to be exposed to psychological violence, measured as exposure to at least one negative behavior associated with psychological violence for the last 6 months on a weekly or more frequent basis. In addition, $45 \%$ of the sample indicated that they witnessed bullying. Based on figures from the Portuguese General Inspectorate of Labor (Inspecção-Geral do Trabalho, 2001) concerning sanctions 
against enterprises due to breach of health and safety legislation, a total of $0.8 \%$ (57 out of 7,013$)$ were about 'moral harassment' or bullying.

The findings of the studies on mobbing in Turkey are similar to the findings of international studies. In one of the studies conducted in health, education and security industries in Bursa, 55\% of 944 employees stated that they have been exposed to psychological mobbing behaviors, and $47 \%$ of the sample stated that they have witnessed such behaviors in the workplace (Bilgel et al, 2006). In another study, with a sample size of 427 employees working in hotels, it was determined that $27,4 \%$ of the sample was exposed to psychological mobbing behaviors (Aydın and Özkul, 2007).

Antisocial behaviors are not limited with psychological mobbing or harassment; there exists many other different behaviors. The cost of such behaviors can be detrimental for organizations. Decision-making, productivity and financial costs at all levels of the organization might be affected by workplace deviant behaviors (Appelbaum et al, 2007); even employees' deviant behaviors may lead to failures of businesses (Hollinger, 1986). Therefore, it is important to understand the effects of such behaviors within the organization. Since these behaviors are considered to be unethical, we believe that presence of ethical leaders and an ethical climate will decrease the occurrence of these behaviors. Accordingly with this study, we aim to analyze the relations of ethical leadership and ethical climate with employees' antisocial behaviors. Within this frame, this study begins with literature review; research methodology, analysis and findings are discussed in the following section, and the last section includes the discussion and conclusion about research findings.

\section{Literature Review}

\section{The Antisocial Behavior of Employees}

Workplace deviant behavior is defined by Robinson and Bennett (1995: 556) as "voluntary behavior that violates significant organizational norms and in doing so threatens the well-being of an organization, its members, or both". Robinson and Bennett (1995) define two types of behaviors related to employee deviance as the ones directed against the organization and the other directed against the coworkers. The first type of behaviors is 'organizational deviance', whereas the second type of behaviors is 'interpersonal deviance'. The authors further separate 'organizational deviance into two as 'production deviance' and 'property deviance', where 'production deviance' is considered to be a minor deviance and 'property deviance' is considered to be a serious deviance. Examples include leaving early, taking excessive breaks, intentionally working slow, wasting resources for 'production deviance' and sabotaging equipment, accepting kickbacks, lying about hours worked, stealing from company for 'property deviance' (Robinson and Bennett, 1995). According to the authors, 'interpersonal deviance', on the other hand, consists of behaviors that occur among coworkers. 'Political deviance', such as gossip, favoritism, blaming coworkers, competing non-beneficially are examples for minor deviance, and 'personal aggression', such as sexual harassment, verbal abuse, bullying, stealing from co-workers and endangering co-workers are examples for serious deviance (Robinson and Bennett, 1995).

'Workplace deviance' has been conceptualized in many ways (i.e. counterproductive work behavior, mobbing/bullying), 'antisocial behavior' being one of these. Robinson and Greenberg (1998) states that there exists no generally agreed upon definition of workplace deviance. Among the most prominent areas of study that relate to deviant behavior are antisocial behavior, counterproductive behavior, dysfunctional behavior, and organizational misbehavior (Kidwell and Martin, 2005:5). The common theme which all of the concepts have is the harmful effect of such behaviors to the organization. In their research, Robinson and O'LearyKelly (1998) use 'antisocial behavior' broadly to describe the negative behaviors in organizations. Giacalone and Greenberg (1997) also describe 'antisocial behavior' as 'any behavior that brings harm, or is intended to bring harm to the organization, its employees, or its stakeholders". According to Giacalone and Greenberg (1997), antisocial behavior focuses more on personal, political, and property interactions and less so on production, with the exception of sabotage (Giacalone \& Greenberg, 1997). Antisocial behavior includes aggression, discrimination, theft, interpersonal violence, sabotage, harassment, lying, revenge and whistleblowing (Kidwell and Martin, 2005).

In order to predict deviant behaviors in the organizations, Hollinger (1986) suggests the importance of personal characteristics and perceptions and attitudes of employees about their employer. Apart from the 
individual factors that affect deviant behaviors, factors related to the organization plays an important role. Sims (1992) indicates that the organization's support or encouragement of such behaviors forms the major reason for the occurrence of these behaviors. In addition, Appelbaum et al (2005) suggest that deviant role models within the organization will lead the employees to have deviant behaviors. Therefore, it is important to consider organizational factors that creates or prevents the occurrence of antisocial behaviors.

\section{Ethical Leadership and the Antisocial Behavior of Employees}

Brown et al (2005: 120) defines ethical leadership as "the demonstration of normatively appropriate conduct through personal actions and interpersonal relationships, and the promotion of such conduct to followers through two-way communication, reinforcement, and decision-making”. Ethical leaders signal to employees that, doing the right thing, is expected, encouraged and valued; in turn employees are more likely to perceive an ethical organizational environment (Mayer et al, 2010:8). According to the authors, ethical leadership is related to various favorable employee outcomes. Therefore, leadership is an important factor which shapes employees' ethical behaviors (Brown et al, 2005). Ethical leadership is found to decrease employee misconduct, deviant behaviors and organizational bullying in the organizations (Mayer et al, 2009, 2010; Stouten et al, 2010; Miao et al, 2012). According to Trevino and Brown (2005), leaders who act unethically will create the appropriate medium for employees' deviant behaviors.

Leader's effect on organization's values is not a new idea. Since people are social beings who are affected from other people, leaders are the important role models in order to foster a favorable ethical climate. Several scholars have presented models of organizational leaders' influences on organizational culture and climates. According to the research findings, there exists a positive relation between leadership and ethical climate (Jose and Thibodeaux, 1999; Pickson et al., 2001; Schminke et al, 2005; Neubert et al, 2009; Mayer et al, 2010). Mendonca (2001:268) notes that, "leaders are responsible for the organization's moral climate that, in effect, reflects the moral development of the leader" and Aronson (2001: 245) states that, "ethical behavior on the part of the leader would appear to be a necessary condition for the establishment of an ethical organization". Treviño et al (2000: 128) discuss the importance of a leader's reputation for ethical leadership, noting that "values are the glue that holds things together, and values must be conveyed from the top of the organization". Dickson et al (2001) suggest that the critical determinant of ethical climate is the leader's ethical behavior. Some scholars (Sims, 2000; Sims and Brinkman, 2002) draw on Schein (1985) to describe how leaders shape and reinforce the ethical climate of an organization. A leader's ethical approach affects an organization's ethical climate (i.e. role modeling, rewards, selection, and communication), they all agree that leaders have substantial power to create and maintain ethical norms and processes, and to create a particular kind of ethical climate (Schminke et al, 2005).

\section{Ethical Climate and the Antisocial Behavior of Employees}

Ethical climate is defined as "the prevailing perceptions of typical organizational practices and procedures that have ethical content" (Victor and Cullen, 1988: 101). Peterson (2002: 50) defines ethical climate as "the shared perceptions of what ethically correct behavior is and how ethical issues should be handled in the organization" and asserts that the climates with a strong emphasis on ethical behavior tend to encounter less workplace deviant behaviors. Victor and Cullen (1988) conclude that ethical climate affects the employee behavior. As an example, the findings of Bartel et al (1998) research indicate a negative relation between ethical climate and ethical violation.

Robinson and Bennett (1995) determined that organization's ethical climate as a good predictor of unethical behavior. Mayer et al (2010:9) indicate that "ethical climates can serve as one cue to help individuals know what types of (un)ethical behaviors are (un)acceptable in the work unit". According to Griffin and Van Fleet (2006), unfavorable culture and ethical climate is one of the factors that trigger workplace deviance. The findings of the meta-analysis study of Martin and Cullen (2006) suggest a negative correlation between positive ethical climates and dysfunctional organizational behavior. Peterson (2002) found out a positive correlation among the type of deviant behavior and the ethical climate of the organization. This study demonstrates that employees are less likely to engage in political deviance when they feel that their organization is concerned for their welfare. 


\section{METHODOLOGY}

\section{Research Goal and the Theoretical Model}

In this study, it was intended to examine how ethical leadership and ethical climate influence the antisocial behaviors of employees. Theoretical model of the research is demonstrated in Figure 1. The following hypotheses are proposed for testing:

H1: Ethical leadership positively influences ethical climate.

H2: Ethical leadership negatively influences the antisocial behavior of employees.

H3: Ethical climate negatively influences the antisocial behavior of employees

H4: Ethical climate has a mediating role in "ethical leadership and employees' antisocial behaviors" relation.

Figure 1: The Theoretical Model

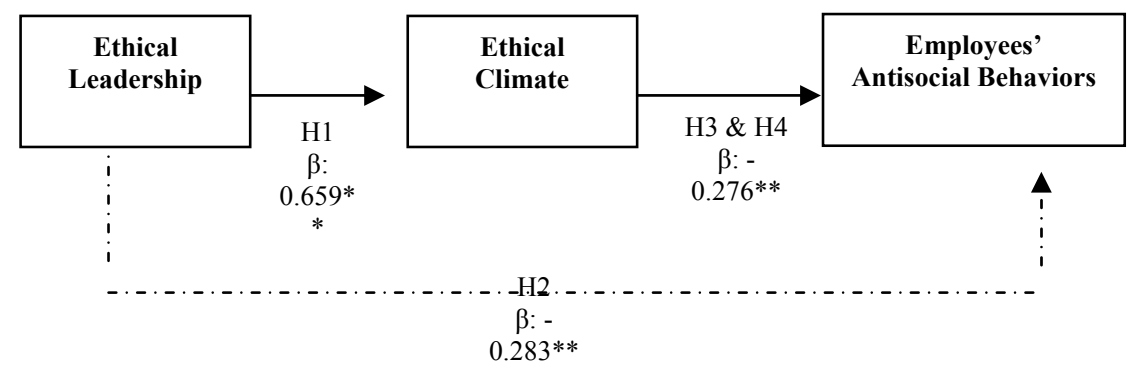

\section{Sample and Data Collection}

Data were collected from 468 employees (of which 271 of them - $\% 57,9 \%$ - are male) from 30 different companies, including energy companies $(19,2 \%)$, municipalities $(17,5 \%)$, education $(\% 23)$, hospitals and hotels $(6 \%)$, technology $(\% 11,4)$, household appliances (white-goods: \% 6,5). Participants' ages ranged from 18 to 57 years, and their tenure in the organization ranged from 1 year to over 58 years; the participants' tenure in their organizations range between 1 to 37 years. Most of the participants $(74,4 \%)$ have a university degree. The occupations of the participants include staff positions $(64,3 \%)$, managerial positions $(23,7 \%)$ and professional positions (10\%). 59\% of the participants are employed in service and education industry, $37 \%$ of them are employed in manufacturing and sales industry and 3,8\% are employed in trade industry.

Employees' perception of the ethical leadership behavior of their superior/immediate authority figure was measured with the Ethical Leadership Scale (ELS), adopted from Brown et al (2005). Employees' perception of the ethical climate of their organizations was measured with the Ethical Climate Scale of Schwepker et al (1997) which is based on the scale of Qualls and Puto (1989). The scale for measuring antisocial behaviors of employees was adopted from Robinson and O'Leary-Kelly (1998). It describes negative behaviors by employees that have the potential to harm individuals and/or the organization. Antisocial behaviors include breaking rules, damaging company property, hurting other workers starting arguments with co-workers, and saying rude things about supervisors or organization etc. Responses were obtained using 5point Likert-type scale where (1) is 'strongly agree' and (5) representing 'strongly disagree'. Data obtained from the participants were analyzed by SPSS statistical package program.

\section{Data Analysis and Findings}

The result of the factor analysis of research variables is presented in Table 1. A strong factor structure is supplied through the factor analyses performed upon variables concerned with ethical leadership, ethical climate and the antisocial behavior of employees. This indicates that the questionnaire statements used to measure these concepts were loaded to the variables. The total variance explained by this analysis is 63,959 . 
Table 1: Factor analysis for ethical leadership, ethical climate and the Antisocial Behavior of Employees

\begin{tabular}{|c|c|c|c|}
\hline & \multicolumn{3}{|c|}{ Components } \\
\hline & 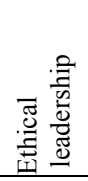 & 䔅 & 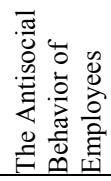 \\
\hline EL9 Has the best interest of employees in mind & ,842 & & \\
\hline EL5 Makes fair and balanced decisions &, 840 & & \\
\hline EL6 Can be trusted & ,835 & & \\
\hline EL8 Sets an example of how to do things the right way in terms of ethics &, 820 & & \\
\hline EL10 When making decisions asks "what is the right thing to do?" & ,792 & & \\
\hline EL2 Defines success not just by results but also by the way that they are obtained & ,784 & & \\
\hline EL7 Discusses business ethics or values with employees & ,764 & & \\
\hline EL3 Listens to what employees have to say & ,748 & & \\
\hline EL1Conducts his/her personal life in an ethical manner & ,670 & & \\
\hline EL4 Disciplines employees who violate ethical standards & ,653 & & \\
\hline EC2 My company strictly enforces a code of ethics & &, 818 & \\
\hline EC3 My company has policies with regards to ethical behavior & & ,797 & \\
\hline EC4 My company strictly enforces policies regarding ethical behavior & & ,780 & \\
\hline $\begin{array}{l}\text { EC6 If a sales executive in my company is discovered to have engaged in unethical behavior } \\
\text { that results primarily in personal gain (rather than corporate gain), she or he will be promptly } \\
\text { reprimanded }\end{array}$ & & ,766 & \\
\hline $\begin{array}{l}\text { EC5 Top management in my company has let it be known in no uncertain terms that ethical } \\
\text { behaviors will not be tolerated }\end{array}$ & & ,762 & \\
\hline EC1 My company has a formal, written code of ethics & & ,744 & \\
\hline $\begin{array}{l}\text { EC7 If a sales executive in my company is discovered to have engaged in unethical behavior } \\
\text { that results in primarily corporate gain (rather than personal gain), she or he will be promptly } \\
\text { reprimanded. }\end{array}$ & & ,728 & \\
\hline EM2 I said or did something to purposely hurt someone at work. & & & ,789 \\
\hline EM9 I said rude things about my supervisor or organization. & & & ,787 \\
\hline EM5 I deliberately bent or broke a rule (s) & & & ,783 \\
\hline EM7 I did something that harmed my employer or boss & & & ,769 \\
\hline EM3 I did work badly, incorrectly or slowly on purpose. & & & ,735 \\
\hline EM8 Started an argument with someone at work & & & ,733 \\
\hline EM1 I damaged property belonging to my employee & & & ,681 \\
\hline EM4 Griped with co-workers & & &, 570 \\
\hline EM6 Criticized people at work & & & ,476 \\
\hline
\end{tabular}

Extraction Method: Principal Component Analysis. Rotation Method: Varimax with Kaiser Normalization.

a Rotation converged in 5 iterations. Total variance explained: 63,959

We have conducted variance analyses in order to develop an understanding of the differences between different variables. According to the results of t-test for gender, there exist differences between females and males concerning their perceptions of ethical leadership and antisocial behaviors, and there exist no difference between the gender groups concerning their perceptions of ethical climate. As it can be inferred 
from Table-2, the perceptions of males of ethical leadership and antisocial behaviors are slightly higher than those of females.

\section{Table 2: T-test for Gender Groups}

\begin{tabular}{|l|l|l|l|l|l|}
\hline Variables & Gender & $\mathbf{N}$ & Mean & Std. Dev. & F \\
\hline Ethical & Female & 194 & 36.418 & .92179 & \multirow{2}{*}{$\mathbf{6 . 9 3 0 *}$} \\
\hline Leadership & Male & $\mathbf{2 6 9}$ & $\mathbf{3 7 . 0 8 5}$ & $\mathbf{. 7 7 4 0 8}$ & \\
\hline \multirow{2}{*}{$\begin{array}{l}\text { Ethical } \\
\text { Climate }\end{array}$} & Female & 194 & 38.814 & .90371 & \multirow{2}{*}{.670} \\
\cline { 2 - 5 } & Male & 269 & 39.442 & .83281 & \\
\hline \multirow{2}{*}{$\begin{array}{l}\text { Antisocial } \\
\text { Behaviors }\end{array}$} & Female & 194 & 11.321 & .23087 & \multirow{2}{*}{$\mathbf{2 5 0 * *}$} \\
\cline { 2 - 5 } & Male & $\mathbf{2 6 9}$ & $\mathbf{1 2 . 1 1 9}$ & $\mathbf{. 4 1 1 8 3}$ & \\
\hline
\end{tabular}

* Significant at the 0.05 level, ** Significant at the 0.01 level,

As for the categorical items having more than two possible answers (i.e. categories), we conducted analyses of variance in order to understand if any variance exists between groups of possible categories of answer for the following questions: business industry and position. Then for those variables that produced significant variance we conducted post hoc Duncan tests, in order to understand the differences of means for each category, where categories of answers are displayed in an ascending order concerning the values of the means on a scale from 1 to 5. The results of the analysis are presented in Table-3. Table-3 shows that levels of ethical leadership, ethical climate and employees' anti-social behaviors are significantly different concerning the different type of business industries and position of the participants.

\section{Table 3: Results of the Analyses of Variance}

\begin{tabular}{|l|l|l|}
\hline & $\begin{array}{l}\text { Business } \\
\text { Industry }\end{array}$ & Position \\
\hline Variables & F & F \\
\hline $\begin{array}{l}\text { Ethical } \\
\text { Leadership }\end{array}$ & $\mathbf{4 . 8 0 3 * *}$ & $2.337^{*}$ \\
\hline Ethical Climate & $\mathbf{1 5 . 4 0 4 * *}$ & $3.225^{* *}$ \\
\hline $\begin{array}{l}\text { Anti-social } \\
\text { Behaviors }\end{array}$ & $\mathbf{1 1 . 4 1 0 ^ { * * }}$ & $13.889^{* *}$ \\
\hline
\end{tabular}

According to the results of the analyses of Duncan tests, the participants working at trade industry have a significantly higher amount of ethical leadership perception when compared to all of the other participants working at other industries (goods/products production and sales, service and manufacturing). The participants working at foods/products production and sales industry have a higher amount of ethical climate perception significantly different from trade and service and manufacturing industries. In addition, the participants working at service and manufacturing industry has a significantly higher amount of the antisocial behavior perceptions when compared with the other two industries.

Senior managers have a significantly lower amount of ethical leadership perception when compared with all of the others. Business partners or bosses have a higher amount of ethical climate perception significantly different from doctors and dentists. And finally, doctors and dentists have a significantly higher amount of perception of the anti-social behaviors than all the other participants.

Means, standard deviations and correlations for all the variables used in this study are presented in Table-4. Correlation Analysis indicates a significant relationship among the variables. As it can be inferred from the Table-4, there exists a negative relation of the antisocial behaviors of employees, respectively with, ethical climate $\left(\mathrm{r}=-, 343^{* *}\right)$, ethical leadership $\left(\mathrm{r}=-, 283^{* *}\right)$, age $\left(\mathrm{r}=-, 163^{* *}\right)$ and tenure $\left(\mathrm{r}=-, 139^{* *}\right)$.

Cronbach alpha is calculated to measure the internal consistency of the reliability of the variables. Reliability coefficient of .70 or higher is considered "acceptable". For this study, the cronbach alpha for the scales are 
$0,856,0,933$ and 0,947 respectively, suggesting that the items have relatively high internal consistency (Table-4).

\section{Table 4: Means, Standard Deviations, Inter-Correlations among Variables and Alpha Reliabilities}

\begin{tabular}{|l|l|r|r|r|r|r|r|r|}
\hline & Variables & $\mathrm{M}$ & $\mathrm{SD}$ & 1 & 2 & 3 & 4 & 5 \\
\hline 1 & Ethical leadership & 3,681 & 0,83883 & $\alpha=0,9478$ & & & \\
\hline 2 & Ethical Climate & 3,918 & 0,86282 & $\mathbf{6 5 9}(* *)$ & $\alpha=0,9330$ & & \\
\hline 3 & Antisocial Behavior of Employees & 1,179 & 0,34958 & $\mathbf{- , 2 8 3}(* *)$ & $\mathbf{- , 3 4 3}(* *)$ & $\alpha=0,8569$ & & \\
\hline 4 & Age of the Institution & 29,61 & 23,35737 & 0,031 & 0,078 & 0,05 & 1 \\
\hline 5 & Age & 33,18 & 7,08298 & $\mathbf{, 1 5 1}(* *)$ & $\mathbf{, 1 8 6}(* *)$ &,$- \mathbf{1 6 3}(* *)$ & $\mathbf{, 1 2 0}(*)$ & 1 \\
\hline 6 & Tenure & 7,488 & 5,90099 & $\mathbf{, 1 6 3}(* *)$ &, $\mathbf{1 9 3}(* *)$ & $\mathbf{- , 1 3 9}(* *)$ & 0,055 &, $\mathbf{7 2 7}(* *)$ \\
\hline
\end{tabular}

* Correlation is significant at the 0.05 level (2-tailed).

** Correlation is significant at the 0.01 level (2-tailed).

Results of the regression analyses are presented in Table-5. According to the results, both ethical leadership and ethical climate affect the antisocial behaviors of employees negatively. In addition, the ethical leadership is found to have a significant positive effect on the ethical climate. However, when regressed together the significant effect of leadership on the behaviors disappear. It is because of the overshadowing effect of the ethical climate; in other words, ethical climate plays a mediating role in the negative relation between ethical leadership and antisocial behaviors. These findings provide support for all of the proposed hypotheses of the study.

Table 5: Effects of Ethical Leadership and Ethical Climate on the Antisocial Behavior of Employees

\begin{tabular}{|r|c|c|c|}
\hline \multirow{2}{*}{} & \multicolumn{2}{|c|}{ Dependent Variables } \\
\cline { 2 - 4 } & Ethical Climate & Model 2: & Model 3: \\
& Employees' Antisocial Behaviors & Employees' Antisocial Behaviors \\
\hline Independent Variables & Standardized $\beta$ Coefficients & Standardized $\beta$ Coefficients & Standardized $\beta$ Coefficients \\
\hline Ethical Leadership & $0.659^{* *}$ & $-0.283^{* *}$ & -0.101 \\
\hline Ethical Climate & & & $-0.276^{* *}$ \\
\hline Adjusted R2 & 0.433 & 0.078 & 0.120 \\
\hline$F$ & $354.453^{* *}$ & $40.201^{* *}$ & $32.351^{* *}$ \\
\hline
\end{tabular}

** Significant at the 0.01 level

\section{CONCLUSION}

With this study, it was mainly aimed to understand the effects of ethical factors on the antisocial behaviors of employees. Antisocial behaviors create important problems for the organizations. These behaviors both negatively affect the employees' own performance and the performance of other employees who are subjected to these behaviors. Therefore, decreasing or eliminating such behaviors is crucial for the organizations. The findings of our study suggest that by creating an ethical environment within the organizations, it is possible to decrease the effects of such behaviors. Leaders with their own principles and applications create an ethical atmosphere in their organizations; hence they enable the ease of ethical behaviors and decrease the occurrence of unethical behaviors. Presence of ethical leaders in the organizations contributes both directly and through developing an ethical climate, to decreasing employees' antisocial behaviors. The existence of an ethical climate perception of employees helps to decrease employees' antisocial behaviors. The results are also consistent with the previous research on this topic. Research findings indicate a negative relation among ethical leadership and deviant behaviors (Brown et al, 2005; 
Mayer et al, 2009). Mayer et al (2010:9) indicate that, if ethical climate is higher in emphasizing ethical actions, employees will be less likely to exhibit unethical behaviors.

Although, this study contributes to the understanding of ethical leadership and ethical climate relation with the antisocial behaviors of employees in Turkey, it also has some limitations. The sample covers companies with comparatively large scale, the study should also be extended to cover the small sized companies since the effect of ethical leaders and presence of an ethical climate might be experienced more within a small group. The findings of this study indicate differences between some of the demographical variables and various industries, in terms of ethical leadership, ethical climate and antisocial behaviors perceptions of the participants. Future research should also concentrate on the perception differences about the influences of ethical leadership and ethical climate on employees' antisocial behaviors. In addition, this research is based on employees' own perceptions for antisocial behaviors; future research might also include the records of the companies about the employees who have behaved antisocially (i.e. mobbing, harassment, theft, lying), thus a more objective data could be derived. Longitudinal studies with inclusion of other possibly related variables such as organizational justice perceptions and reward systems are also suggested for further research.

It can be expected that antisocial behaviors of employees decrease when such demographic characteristics as age and tenure increase. But managers need not to wait until their employees get older to behave less antisocially, instead they may try to behave themselves as more ethical leaders and try to establish a more ethical milieu to work, then of course they may expect from their employees much desirable behaviors. According to Plinio et al (2010), the most important problem of the organizations is the nonexistence of ethical leaders. As the results of this study also indicate, realizing the benefits of ethical leaders for strengthening ethical climate and decreasing antisocial behaviors of employees, the organizations should select and educate ethical leaders. 


\section{REFERENCES}

Appelbaum, S.H., Deguire, K.J. and Lay, M. (2005), The Relationship of Ethical Climate to Deviant Workplace Behavior', Corporate Governance, 5(4), pp. 43-56.

Appelbaum, S.H., Iaconi, G.D. and Matousek, A. (2007), Positive and Negative Deviant Workplace Behaviors: Causes, Impacts and Solutions, Corporate Governance, 7(5), pp.586-598.

Aronson, E. (2001), Integrating Leadership Styles and Ethical Perspectives, Canadian Journal of Administrative Sciences, 18, pp. 244-256.

Aydın, Ş. And Özkul, E. (2007), "İşyerinde Yaşanan Psikolojik Şiddetin Yapısı ve Boyutları: 4-5 Yıldızlı Otel İşletmeleri Örneğị”, Anadolu Üniversitesi Sosyal Bilimler Dergisi, 7(2), pp.169-186.

Bartels, L., Harrick, E., Martell, K. and Strickland, D. (1998), The Relationship between Ethical Climate and Ethical Problems within Human Resource Management, Journal of Business Ethics, 17, pp.799-804.

Bilgel, N; Aytac, S; Bayram, N. (2006), Bullying in Turkish White-Collar Workers, Occupational MedicineOxford, 56 (4), pp. 226-231.

Brown, M.E., Trevino, L.K. and Harrison, D.A. (2005), Ethical Leadership: A Social Learning Perspective for Construct Development and Testing, Organizational Behavior and Human Decision Processes, 97, pp.117-134.

Dickson, M.W, Smith, D.B., Grojean, M.W. and Ehrhart; M (2001), An Organizational Climate Regarding Ethics: The Outcome of Leader Values and The Practices that Reflect Them, The Leadership Quarterly,http://www.sciencedirect.com/science/journal/10489843/12/2 12(2), pp.197-217.

Giacalone, R.A. and Greenberg, J. (1997), Antisocial Behavior in Organizations, Thousand Oaks, CA: Sage.

Griffin, R.W. and Van Fleet, D.D. (2006), Dysfunctional Organization Culture: The Role of Leadership in Motivating Dysfunctional Work Behaviors, Journal of Managerial Psychology, 21(8), pp. 698-708.

Hollinger, R.C. (1986), Acts against the Workplace: Social Bonding and Employee Deviance, Deviant Behavior, 7, pp.53-75.

Inspecção-Geral do Trabalho (Portugal) (2001), The Report of the General Inspectorate of Labour, Lisbon.

Jose, A. and Thibodeaux, M.S. (1999), Institutionalization of Ethics: The Perspective of Managers, Journal of Business Ethics, 22(2), pp.133-143.

Kidwell, R.E. and Martin, C.L. (2005), The Prevalence (and Ambiguity) of Deviant Behavior at Work: An Overview, in Kidwell, R.E. and Martin, C.L. (Eds) "Managing Organizational Deviance", Sage Publications, London, pp: 1-37.

Martin, K. and Cullen, J. (2006), Continuities and Extensions of Ethical Climate Theory: A Meta-Analytic Review, Journal of Business Ethics, 69, pp.175-194.

Mayer, D.M., Kuenzi, M., Greenbaum, R., Bardes, M. and Salvador, R. (2009). How low does Ethical Leadership Flow? Test of a Trickle-Down Model, Organizational Behavior and Human Decision Processes, 108 , pp.1-13.

Mayer, D.M., Kuenzi, M. and Greenbaum, R.L. (2010), Examining the Link between Ethical Leadership and Employee Misconduct: The Mediating Role of Ethical Climate, Journal of Business Ethics, 95, pp.7-16.

Mendonca, M. (2001), Preparing for Ethical Leadership in Organizations, Canadian Journal of Administrative Sciences, 18, pp.266-276.

Miao, Q., Newman, A., Yu, J. and Xu, L. (2012), The Relationship Between Ethical Leadership and Unethical Pro-Organizational Behavior: Linear or Curvilinear Effects?, Journal of Business Ethics, pp.1-13.

Neubert, M.J., Carlson, D.S., Kacmar, K.M., Roberts, J.A. and Chonko, L.B. (2009), The Virtuous Influence of Ethical Leadership Behavior: Evidence from the Field, Journal of Business Ethics, 90, pp.157-170. 
Peterson, D.K. (2002), Deviant Workplace Behavior and the Organization's Ethical Climate, Journal of Business and Psychology, 17(1), pp.47-61.

Piñuel y Zabala, I. (2002), La Incidencia Del Mobbing ó Acoso Psicológico en el Trabajo in España, Unpublished study, Universidad de Alcala.

Plinio, A. J., Young, J.M. and Lavery, L.M. (2010), The State of Ethics in Our Society: A Clear Call for Action, International Journal of Disclosure and Governance, 7, pp.172-197.

Qualls, W.J. and Puto, C.P. (1989), Organizational Climate and Decision Framing: An Integrated Approach to Analyzing Industrial Buying Decisions, Journal of Marketing Research, 26 (May), pp.179-192.

Robinson, S. and Bennett, R. (1995), A Typology of Deviant Workplace Behaviors: A Multidimensional Scaling Study, Academy of Management Journal, 38(2), pp.555-572.

Robinson, S.L. and Greenberg, J. (1998), Employees Behaving Badly: Dimensions, Determinants and Dilemmas in the Study of Workplace Deviance, Journal of Organizational Behavior (1986-1998), pp. 1-30.

Robinson, S.L. and O'Leary-Kelly, A.M. (1998), Monkey See, Monkey Do: The Influence of Work Groups on the Antisocial Behavior of Employees, Academy of Management Journal, 41, pp.658-672.

Schein, E. (1985), Organizational Culture and Leadership, Jossey-Bass: San Francisco, CA.

Schminke, M.,M. Ambrose and D. Neubaum (2005), The Effect of Leader Moral Development on Ethical Climate and Employee Attitudes', Organizational Behavior and Human Decision Processes 97, pp.135-151.

Schwepker, C.H., Jr., Ferrell, O.C. and Ingram, T.N. (1997), The Influence of Ethical Climate on Role Stress in the Sales Force, Journal of the Academy of Marketing Science, 25 (Spring), pp.99-108.

Sims, R.R. (1992), The Challenge of Ethical Behavior in Organizations', Journal of Business Ethics, 11, pp.505-513.

Sims, R.R. (2000), Changing an Organization's Culture under New Leadership, Journal of Business Ethics, 25 , pp. 65-78.

Sims, R.R. and Brinkman, J. (2002), Leaders as Moral Role Models: The Case of John Gutfreund at Salomon Brothers, Journal of Business Ethics, 35, pp.327-339.

Stouten, J., Baillien, E., Broeck, A.V., Camps, J., Witte, H.D. and Euwema, M. (2010), Discouraging Bullying: The Role of Ethical Leadership and its Effects on the Work Environment, Journal of Business Ethics, 95(1), pp.17-27.

Treviño, L.K., Hartman, L.P. and Brown, M. (2000), Moral Person and Moral Manager: How Executives Develop a Reputation for Ethical Leadership, California Management Review, 42, pp.128-142.

Trevino, L.K. and Brown, M.E. (2005), The Role of Leaders in Influencing Unethical Behavior in the Workplace', in Kidwell, R.E. and Martin, C.L. (Eds), Managing Organizational Deviance, Sage Publishing, London, pp. 69-96.

Victor, B. and Cullen, J.B. (1988), The Organizational Bases of Ethical Work Climates, Administrative Science Quarterly, 33, pp.101-125.

Vittorio D.M., Hoel, H. and Cooper, C.L. (2003), Preventing Violence and Harassment in the Workplace, Luxembourg: Office for Official Publications of the European Communities. 